REVISTA DE GEOCIÊNCIAS DO NORDESTE

\title{
ÍNDICE DE GEODIVERSIDADE DO PARQUE NACIONAL DE UBAJARA, CEARÁ, BRASIL
}

\section{Suedio Alves Meira' ${ }^{\mathbf{1}}$ Edson Vicente da Silva ${ }^{2}$}

${ }^{1}$ Doutorando em Geografia, Departamento de Geografia, Universidade Federal do Ceará (UFC), Fortaleza/CE, Brasil. ORCID: https://orcid.org/0000-0001-9059-8787.

Email: suediomeira@gmail.com

${ }^{2}$ Doutor, Departamento de Geografia, Universidade Federal do Ceará (UFC), Fortaleza/CE, Brasil.

ORCID: https://orcid.org/0000-0001-5688-750X.

Email: cacauceara@gmail.com

\section{Resumo}

A quantificação da geodiversidade, definida pela variedade de elementos abióticos e processos associados, é uma ferramenta importante na distinção de locais mais ou menos geodiversos. O presente artigo apresenta como objetivo aplicar um índice de geodiversidade ao território do Parque Nacional de Ubajara, Ceará. A metodologia partiu do levantamento de referencial teórico e dados cartográficos. Posteriormente foi empregada uma metodologia de quantificação difundida em escala nacional e confeccionados mapas temáticos para melhor exposição dos resultados. O índice demonstrou que as áreas mais geodiversas estão localizadas na porção central do Parque Nacional de Ubajara, zona caracterizada pelo degrau geomorfológico entre o Glint da Ibiapaba e a Superfície Sertaneja. Essa descontinuidade do relevo influencia na organização da rede de drenagem, na configuração dos solos e nas unidades morfológicas.

Palavras-chave: Glint da Ibiapaba; Quantificação; Geociências.

\section{GEODIVERSITY INDEX IN THE UBAJARA NATIONAL PARK, CEARÁ, BRAZIL}

Abstract
The geodiversity quantification is an important tool to distinguish
locations that are more or less geodiverse. This article aims to
apply a geodiversity index in the Ubajara National Park. The
methodology starts from the theoretical review and cartographic
data. Later, we employ a quantification method in a national scale
and build thematic maps for better result exposition. The index
demonstrates that the areas with greater diversity in the park
central portion, a zone characterized by the geomorphological

degree between the Ibiapaba Glint and the Sertaneja Surface. This discontinuity in the landscape has influence in the drainage net, soil configuration and morphological units.

Keywords: Ibiapaba Glint; Quantification; Geosciences.

\section{INDICE DE GEODIVERSDAD DEL PARQUE NACIONAL DE UBAJARA, CEARÁ, BRASIL}

\section{Resumen}

La cuantificación de la geodiversidad, definida por la variedad de elementos abióticos y procesos asociados, es una herramienta importante para distinguir los sitios más o menos geodiversos de un territorio. Este artículo tiene como objetivo aplicar un indice de geodiversidad al territorio del Parque Nacional Ubajara, Ceará. La metodología empleada parte de la encuesta del marco teórico y de los datos cartográficos. Posteriormente, se utilizó una metodología de cuantificación difundida a escala nacional y se prepararon mapas temáticos para una exposición gráfica de los resultados. El índice mostró que las áreas más geodiversas están ubicadas en la porción central del Parque Nacional Ubajara, un área caracterizada por el paso geomorfológico entre el Glint de la Ibiapaba y la Superficie Sertaneja. Esta discontinuidad del relieve influye en la organización de la red de drenaje, la configuración de los suelos y las unidades morfológicas.

Palabras-clave: Glint de la Ibiapaba; Cuantificación; Geociencias.

\section{INTRODUÇÃO}

A avaliação quantitativa da Geodiversidade por meio da aplicação de índices tem adquirido espaço na temática nas últimas décadas. Em escala global diversos modelos foram desenvolvidos no intuito de classificar áreas de acordo à diversidade de elementos abióticos. As metodologias oferecem como objetivos auxiliar no planejamento territorial e orientar o desenvolvimento de trabalhos científicos, uma vez que diferenciam locais mais ou menos geodiverso.

A possibilidade de mensuração e de quantificação da geodiversidade são discutidas desde os primeiros estudos desse novo paradigma das geociências, que iniciou seus estudos enquanto campo teórico na década de 1990. Uma das primeiras 
tentativas metodológicas de quantificação foi realizada por Cedrero (1996), que propôs que a variedade de elementos de interesse geológico, em particular o valor intrínseco, seja um dos critérios considerados.

Manosso (2012), expõe a escassez de métodos de quantificação que realizam uma análise integrada. Segundo o autor, as apropriações de métodos de compartimentação geomorfológica são relevantes na realização de uma análise sistêmica, uma vez que essas são construídas por meio da interação de critérios relativos à estrutura, à forma, aos processos e ao clima. Serrano e Ruis-Flaño (2007) propõem um índice de geodiversidade que relaciona a variedade de ambientes físicos (geologia, relevo, hidrologia, etc.) com a rugosidade do relevo e unidades geomorfológicas previamente estabelecidas.

Nas metodologias de avaliação quantitativa da geodiversidade predominam duas correntes. A primeira considera a atividade enquanto "fio condutor" de trabalhos de identificação do geopatrimônio (aqui entendido enquanto sinônimo de patrimônio geológico). A segunda realiza uma análise holística e aborda a avaliação enquanto a quantificação da diversidade abiótica natural (PEREIRA et al., 2013).

Salientasse que, o presente autor coaduna com a segunda corrente, concebendo que a geodiversidade e o geopatrimônio apresentam metodologias de análises distintas, não havendo uma relação entre geodiversidade e o número de geossítios de um local. Porém, considera que estudos de quantificação podem ser utilizados como auxílio na etapa de inventariação do geopatrimônio, especialmente em áreas de grandes dimensões, para conter gastos com trabalhos de campo durante as estratégias de geoconservação.

Pereira et al (2013), desenvolvem um índice de geodiversidade obtido a partir da soma do número de elementos e ocorrências abióticas em uma grade ( $g$ rid) pré-estabelecido. A metodologia proposta é calculada por meio da sobreposição de diferentes mapas e apresenta enquanto potencialidade a aplicação em áreas de dimensões variadas.

Diante o exposto, o presente estudo tem como objetivo aplicar um índice de geodiversidade para a área do Parque Nacional de Ubajara (PNU), seguindo a metodologia proposta por Pereira et al. (2013), para diferenciar áreas mais ou menos geodiversas. O PNU é uma Unidade de Conservação (UC) de proteção integral federal localizada no noroeste do estado do Ceará e que engloba os municípios de Ubajara, Tianguá e Frecheirinha, sendo caracterizada pela principal província espeleológica do estado.

\section{METODOLOGIA}

Para a quantificação foi utilizada a metodologia de Pereira et al. (2013). O índice é composto pela sobreposição de mapas temáticos sobre uma grade definida com base na área em análise. Sendo assim, as escalas dos dados inseridos na matriz contribuem para um maior detalhamento da informação gerada.

Os detalhamentos dos dados configuraram uma dificuldade no caso do PNU, já que os disponíveis estão em escalas bastante generalistas, como o mapa geológico em escala de 1:1.000.000 (CPRM, 2014), o mapa de solo em escala de 1:600.000 (EMBRAPA, 1973) e o mapeamento de registros fósseis realizado pela CPRM em caráter exploratório. Outro fato a ser salientado foi a ausência de dados referentes aos recursos minerais, sendo esse campo retirado. Devido aos dados utilizados, o mapa final proposto apresenta escala de 1:1.000.000.

As distâncias da grade definida foi de 1,5x1,5 km (Figura 1). As extensões foram estabelecidas buscando integrar o maior número de quadras na área, especialmente diante do caráter alongado da mesma com $23 \mathrm{~km}$ no sentido norte-sul e apenas $5 \mathrm{~km}$ na orientação leste-oeste, no final a grade contou com 56 quadriculas para o perímetro. A demarcação da grade regular e a confecção dos mapas foram realizados no programa ArcGis 10.3.

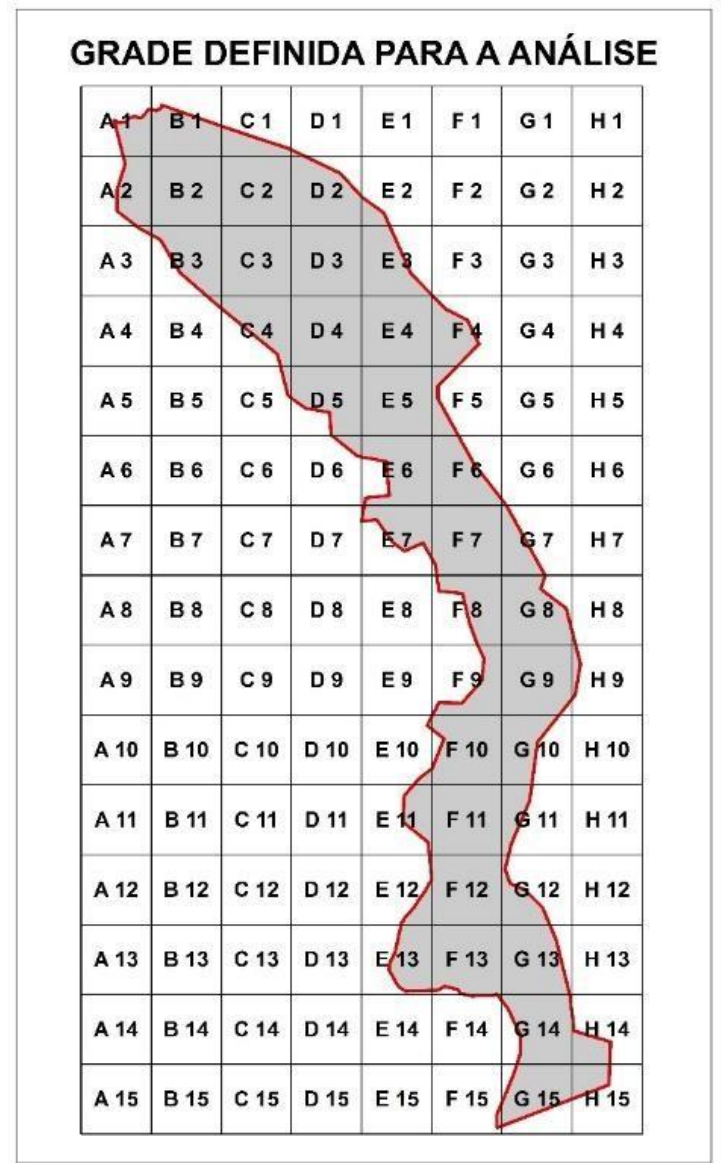

Figura 1 - Grade definida para o cálculo do índice de geodiversidade do Parque Nacional de Ubajara. Fonte: autores.

Após a definição da grade foi possível atribuir o número de elementos relativos aos índices individuais adotados, os quais foram compostos pelos índices geológico, geomorfológico, paleontológico e de solo. A definição dos valores adotados em cada índice individual pode ser visualizada no Tabela 1.

\section{RESULTADOS E DISCUSSÃO}

$\mathrm{O}$ índice de geologia variou entre 3 e 11 pontos (Tabela 2). Os maiores valores se estendem na parte central do PNU, estando dispostos na zona de contrato entre as rochas sedimentares da Província Parnaíba (Grupo Serra Grande) e as rochas do Subdomínio do Médio Coreaú (Província Borborema). 
A Província Borborema estendesse por aproximadamente 450 mil km² no nordeste brasileiro. A Província Borborema vem sendo trabalhada desde a formação do megacontinente Atlântica, no Paleoproterozoico, sendo composta por uma diversidade de unidades geológicas relacionadas à Orogênese Brasiliana, a qual ocorreu do Proterozóico Superior ao Paleozoico Superior (CLAUDINO-SALES; LIMA, 2011). Como salienta Amaral (2007, p. 10), a evolução da Província Borborema "está relacionada à convergência e aglutinação dos crátons OesteAfricano, Amazônico e São Francisco-Congo, durante a formação da porção ocidental de Gondwana".

Tabela 1 - Índices individuais aplicados na definição quantitativa da Geodiversidade. Fonte: autores.

Foi atribuído 1 ponto para cada litologia presente. Foi somado 1 ponto ao quadro com unidades estruturais, o que na área foi expresso pela Falha Arapá, que se Índice Geológico entende apenas pelos quadrantes B1 e B2. Os dados utilizados teve como fonte mapeamentos realizados pelo Serviço Geológico Brasileiro na escala de 1:1.000.000 (CPRM, 2014).

O índice geomorfológico é composto por dois sub-índices.

Sub-índice de Relevo: foram definidas as Unidades Morfoestruturais, Morfoesculturais e Morfológicas da área de pesquisa. Foi atribuído um ponto para cada unidade morfológica, sendo adicionado 1 ponto para quadras que apresentassem zonas de contato entre unidades morfoestruturais distintas, por Índice entender que são áreas de elevada Geomorfológico alteração morfológica (ARRUDA; BARRETO, 2015). Para a definição das unidades foram utilizados dados de geologia (CPRM, 2014) e análise de imagens SRTM.

Sub-índice de Hidrografia: foi atribuído o valor 1 para todos os quadrantes com cursos hídricos. Os dados utilizados foram oriundos da extração de drenagem realizada por meio do programa ArcGis 10.3, tendo como base imagens SRTM.

Para o índice paleontológico foram utilizados dados da CPRM (2014). Foi atribuído 1 ponto para cada fóssil Índice documentado, porém foi encontrado Paleontológico apenas um registro, estando esse localizado no quadrante F13. O registro compreende uma espécie da megafauna pleistocênica.

Definido pela soma dos diferentes tipos de solo. Foi atribuído 1 ponto para cada Índice de Solos EMBRAPA (1973) na escala de $1: 600.000$.

O PNU está inserido no contexto do Subdomínio Médio Coreaú representando importantes falhamentos e lineamentosprécambrianos, sendo delimitado a leste pela zona de cisalhamento Sobral-Pedro II que faz parte do Lineamento Transbrasiliano (CLAUDINO-SALES; LIMA, 2011). Moura-Fé (2015) expõe que o Subdomínio do Médio Coreaú é composto pela sucessão de falhas paralelas dispostas em direção NE-SO, asquais orientam uma sucessão de estruturas de horsts (Granja e Tucunduba) e grábens (Martinópole e Ubajara-Jaibaras). No PNUas litologias pertencentes ao subdomínio Médio Coreaú integram o Grupo Martinópole (Formação São Joaquim) e o Grupo Ubajara (formações Caiçaras, Coreaú, Frecheirinha e Trapiá).

Tabela 2 - Relação dos valores encontrados para nos subindices. Fonte: autores.

\begin{tabular}{l|l|l}
\hline $\begin{array}{l}\text { Valor do Índice de } \\
\text { Geologia }\end{array}$ & $\mathbf{N}^{\mathbf{0}}$ de quadras & \% das quadras \\
\hline 3 & 18 & $32,14 \%$ \\
\hline 4 & 15 & $26,79 \%$ \\
\hline 6 & 2 & $3,57 \%$ \\
\hline 7 & 16 & $28,57 \%$ \\
\hline 10 & 3 & $5,36 \%$ \\
\hline 11 & 2 & $3,57 \%$ \\
\hline $\begin{array}{l}\text { Valor do Índice de } \\
\text { Geomorfologia }\end{array}$ & $\mathbf{N}^{\mathbf{0}}$ de quadras & $\%$ das quadras \\
\hline 1 & 10 & $17,85 \%$ \\
\hline 2 & 12 & $21,43 \%$ \\
\hline 3 & 15 & $26,79 \%$ \\
\hline 4 & 12 & $21,43 \%$ \\
\hline 5 & 7 & $12,50 \%$ \\
\hline $\begin{array}{l}\text { Valor do Índice de } \\
\text { Solos }\end{array}$ & $\mathbf{N}^{\mathbf{0}}$ de quadras & $\%$ das quadras \\
\hline 1 & 19 & $33,93 \%$ \\
\hline 2 & 31 & $55,36 \%$ \\
\hline 3 & 6 & $10,71 \%$ \\
\hline
\end{tabular}

No extremo norte da área ocorre a Formação São Joaquim, que segundo Siqueira $(2011$, p. 21) é composta principalmente por "quartzitos com variável composição mineralógica, incluindo minerais como cianita, silimanita e muscovita com intercalações menores de calcissilicáticas, xistos e metavulcânicas félsicas". O Grupo Ubajara é uma sequência vulcano-sedimentar plataformal de idade Neoproterozoica (650-850 Ma). É composto da base para o topo pelas formações Caiçaras (pelitos-psamitos, arenitos finos), Trapiá-Frecheirinha (arenitos e calcários) e Coreaú (arenitos e grauvacas) (CAVALCANTE et al., 1993).

A Província Parnaíba abrange "a Bacia Sedimentar do Parnaíba e as rochas do embasamento pré-cambriano que afloram imediatamente a norte da mesma, ocupando uma área de aproximadamente $650.000 \mathrm{~km}^{2}$ " (CHAMANI, 2015, p. 6). A Bacia Sedimentar do Parnaíba, inserida na Província Parnaíba, apresenta forma elíptica arredondada estando disposta por mais de 600 mil km² entre os estados do Piauí, Maranhão, Bahia, Ceará, Pará e Tocantins. Configura-se enquanto um dos cinco depósitos intracontinentais de idade Paleozoica da América do Sul, sendo denominada de sinéclise, por ser uma região deprimida 
em meio a uma plataforma. Foi originada por uma lenta subsidência oriunda do estabelecimento de alguns grábens inicialmente rifteados (VAZ et al., 2007).

No PNU afloram rochas do Grupo Serra Grande, o qual teve sua gênese no Siluriano, sendo a primeira supersequência de deposição sedimentar da Bacia do Parnaíba, estando sobreposta ao embasamento cristalino (VAZ et al., 2007; SANTOS; CARVALHO, 2009). Caputo e Lima (1984) expõe que no contexto da Bacia do Parnaíba a seção Serra Grande é uma das mais discutidas quanto à idade, subdivisões e ambiente de sedimentação, sendo desses autores a subdivisão atualmente aceita do grupo em formações Ipu, Tianguá e Jaicós.

As quadras B1 e B2 apresentam os maiores valores (11 pontos), já que além de estarem no contato entre diversas formações geológicas, apresentam elemento estrutural, caracterizado pela falha Arapá. Outra área de valores elevados são as quadriculas E13, F12 e F13, que compreendem o contato entre as Formações Frecheirinha e Coreaú com o Grupo Serra Grande. Nessa área afloram metacalcários que permitem a formação do relevo cárstico característico do PNU.

Os menores índices estão localizados nos limites leste e oeste do PNU, são área que apresentam apenas uma formação geológica (3 e 4 pontos), compreendem aproximadamente 59\% das quadras mapeadas. É válido salientar que a ausência de dados de mapeamento de afloramentos influencia nos dados finais, os quais poderiam apresentar maior diversidade.

O índice de geomorfologia apresentou variação entre 1 e 5 pontos (Tabela 2). O Parque Nacional de Ubajara apresenta duas unidades morfoestruturais, o Glint da Ibiapaba, localizada na porção oeste com rochas sedimentares e topografia elevada e plana, e as Superfícies Sertaneja, localizada na porção leste com rochas metamórficas fraturadas por ações tectônicas e erodidas por pulsos climáticos pós-cretáceo.

Com base nas unidades morfoesculturas definidas por MouraFé (2015) para a Ibiapaba Setentrional, notasse que na área ocorrem as Superfícies de Cimeira, as Superfícies de Base e o Relevo Cárstico. As Superfícies de Cimeira são caracterizadas pelo Glint da Ibiapaba que, com seus mais de 900 metros, se apresenta enquanto um sobressalto altimétrico. Segundo MouraFé (2015, p. 185), a "altimetria atual parece estar estabelecida praticamente desde o seu soerguimento, em função da resistência intempérico-erosiva da camada capeadora de arenitos do Grupo Serra Grande ao downwearing e da ausência de indicadores em campo".

Apesar da altitude conservada a Ibiapaba já apresentou uma dimensão espacial maior, sendo que o processo de diminuição de sua área foi dado pelo recuo das vertentes (backwearing). A presença da cornija arenítica sobrepondo o escarpamento da Ibiapaba, possibilitou um recuo mais lento das vertentes, já que a litologia é mais resistente que as rochas metamórficas que a sustentam (MOURA-FÉ, 2015).

A diferença de resistência entre as litologias presentes no Grupo Serra Grande e as rochas metamórficas a leste possibilitou o avanço dos processos erosivos e a formação da segunda morfoescultura da área, as Superfícies de Base. Essas áreas compreendem as Superfícies Sertaneja e as pequenas planícies fluviais da porção leste do PNU. Na formação dessa morfoescultura o processo de downwearing é mais relevante. Tanto que a diferença entre as cotas altimétricas das unidades, na área de pesquisa, se aproximam dos 700 metros em menos de $5 \mathrm{~km}$. A última morfoescultura é caracterizado pelo revelo cárstico desenvolvido nos metacalcários da formação Frecheirinha. É possível distinguir feições exocársticas, como os cones cársticos e as lápias, e endocársticas, como as furnas e as cavernas.

Quanto as unidades morfológicas foram identificadas três, sendo elas: i) Topo do Planalto da Ibiapaba: localizada na porção oeste do PNU, são as áreas mais elevadas da UC e com baixos índices de declividade; ii) Glint da Ibiapaba, zona caracterizada pelo degrau altimétrico presente na área, são área de grande declividade, sendo adotado o valor superior a $15^{\circ}$, juntamente da análise de imagens SRTM, para a compartimentação dessa unidade. Essa unidade compreende a escarpa e os depósitos coluvionais; e, iii) Depressão sertaneja, áreas mais rebaixadas e com relativa mamemolização que estão localizadas no limite leste da unidade de conservação.

O sub-índice de drenagem demonstrou que 38 das 56 quadriculas $(67,86 \%)$ contem cursos hídricos. A rede dedrenagem do PNU é composta por rios de primeira e segunda ordem, com baixa vazão e, na maioria dos casos, de caráter intermitente. As quadras que não dispõem de drenagem estão localizadas na porção oeste do parque, sendo áreas planas e com altitudes elevadas, ou naquelas que apresentam apenas uma pequena parte na área de análise, como exemplo as D1, G8, H6.

Após a junção dos sub-índices de geomorfologia notasse que os maiores valores estão localizados na zona de contato entre as unidades morfoestruturais, porção central do PNU. Essa área é caracterizada por uma mudança abrupta do relevo, maiores índices de declividade e por zonas de ressurgência da rede de drenagem. Os conjuntos de quadriculas E5, E6 e F10, F11, F12, F13, G14 apresentaram os maiores índices englobando todas as unidades morfológicas, sendo área de contato entre unidades morfoestruturais e dispondo de rede de drenagem. Os menores valores estão localizados nos estremos leste e oeste da UC.

Quanto ao índice paleontológico, apenas uma quadricula apresentou pontuação, a F13. As características sobre o registro fóssil encontrado foram descritas anteriormente. Os dados referentes a distribuição do índice de solo podem ser visualizados na Tabela 2. No Parque Nacional de Ubajara ocorrem Argissolos, Latossolos Amarelos distróficos e Neossolos eutrófico e distróficos, sendo que nas quadras há o predomínio de ocorrência de mais de um tipo (tabela 2).

As quadras E6, F7, F8, F10, F13 e G15 se destacam por agrupar todos os tipos de solos, são quadras que apresentam porções tanto nas áreas elevadas do Glint da Ibiapaba, onde a o predomínio dos Latossolos, na zona de front, onde se desenvolvem os Neossolos, e nas áreas da superfície sertaneja, que concentram os Argissolos. Por sua vez, as quadras que apresentam apenas um tipo de solo estão dispostas, em sua maioria, na extremidade leste do parque.

Ao analisar o índice de geodiversidade do PNU é possível visualizar que a maioria das quadriculas apresentam-se na classe muito baixa (Tabela 3 ), sendo essas localizadas nas extremidades leste e oeste da UC (Figura 2). São locais com apenas uma formação geológica, longe do contato entre domínios estruturais e com apenas um tipo de solo. É válido ressaltar as quadras G6 e H8 que apresentaram os menores valores (5), as quais abarcam no seu interior apenas 0,57 e 1 ha, respectivamente, da área de pesquisa. Uma característica dessa classe é englobar quadras com 
pouca extensão territorial, tanto que mesmo concentrando $41,08 \%$ das quadriculas dispõem de menos de $15 \%$ da área total da UC (940,09 ha).

Tabela 3 - Relação dos valores encontrados para o Índice de Geodiversidade. Fonte: autores

\begin{tabular}{l|l|l|l}
\hline $\begin{array}{c}\text { Valor do Índice de } \\
\text { Geodiversidade }\end{array}$ & $\begin{array}{l}\mathbf{N}^{\mathbf{0}} \text { de } \\
\text { quadras }\end{array}$ & $\begin{array}{l}\text { \% de } \\
\text { quadras }\end{array}$ & Área Total \\
\hline Muito Baixo & 23 & $41,08 \%$ & 940,09 ha \\
\hline Baixo & 11 & $19,64 \%$ & $1337,73 \mathrm{ha}$ \\
\hline Médio & 10 & $17,85 \%$ & $1700,75 \mathrm{ha}$ \\
\hline Alto & 8 & $14,29 \%$ & $1501,67 \mathrm{ha}$ \\
\hline Muito Alto & 4 & $7,14 \%$ & $800,96 \mathrm{ha}$ \\
\hline
\end{tabular}

O índice de geodiversidade baixo compreendeu 11 quadras, totalizando 1337,73 ha do PNU (Tabela 3). Essas áreas apresentaram valores entre 8 e 10 pontos e se localizam próximas aos limites leste e oeste do parque (Figura 2), em contato com as quadras de valor muito baixo. Essa classe não apresenta contato entre unidades morfoestruturais, um ou dois tipos de solos e apenas uma formação litológica, com exceção da quadra G12 que apresenta rochas das formações Frecheirinha e Coreaú, o que propiciou um maior índice, sendo ela a única quadra a obter 10 pontos.

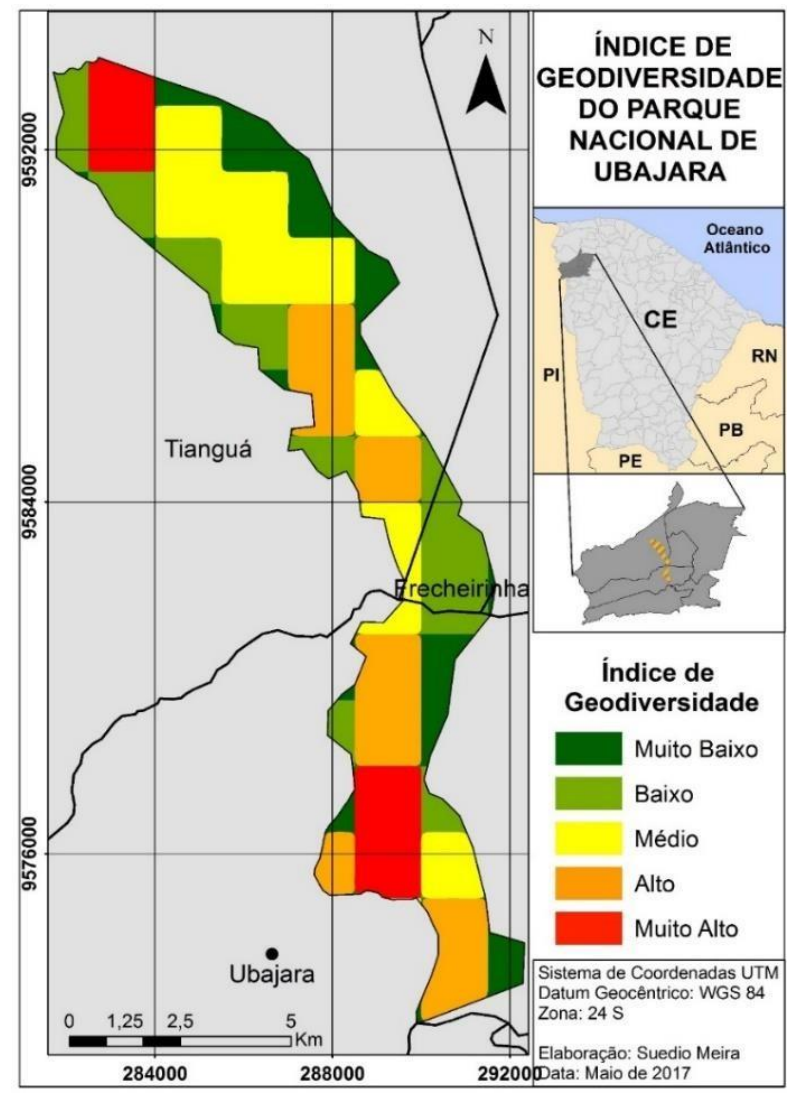

Figura 2 - Representação do Índice de Geodiversidade do Parque Nacional de Ubajara. Fonte: autores
Maior parte do PNU apresenta índice médio, com 1700,75 ha disposto em 10 quadras (Tabela 3), variam entre 11 e 13 pontos. As quadriculas estão localizadas na porção central (Figura 2), sendo que englobam duas formações litológicas, contato entre morfoestruturais (com exceção da quadra F14, que está totalmente inserida no Planalto da Ibiapaba) e dois tipos de solos (com ressalva a quadra F8 que conglomera todos os tipos de solo). As quadriculas F14 e G13 se diferem no quesito unidades morfológicas por apresentarem uma e três unidades, respectivamente, enquanto as demais compreendem duas unidades. Quanto à presença de rede de drenagem apenas as quadras F14 e F9 não pontuaram.

$\mathrm{O}$ índice de geodiversidade alto, que compreende valores entre 14 e 16 pontos, englobou 8 quadras, numa área referente à 1501,67 ha do PNU (Tabela 3). São áreas composta por duas formações litológicas, com ressalva a quadra E13 que englobou três formações (Grupo Serra Grande, Formações Coreaú e Frecheirinha), fato que corroborou para que ela fosse a única a atingir 16 pontos. Todas as quadriculas apresentam rede de drenagem, estão no contato entre as duas grandes unidades morfoestruturais e possuem ao menos duas unidades morfológicas. Estão dispostos em três zonas do PNU, uma na porção central da unidade de conservação (E5, E6, F7), no interior ou às margens do antigo perímetro do parque $(\mathrm{E} 13, \mathrm{~F} 10, \mathrm{~F} 11) \mathrm{e}$ no extremo sul da área (G14 e G15).

Apenas 4 quadras apresentam índice de geodiversidade muito alto, com valores iguais ou acima de 17 , sendo a menor classe em área no PNU com 800,96 ha (Tabela 3). Estão dispostas em duas áreas distintas, uma ao norte da UC, compreendendo as quadras B1 e B2, e a outra zona centro-sul, abrangendo as quadras F12 e F13, local onde há o desenvolvimento do relevo cárstico. Todas essas áreas englobam contato morfoestrutural.

As quadras B1 e B2 apresentam rochas do Grupo Serra Grande e das Formações Coreaú e São Joaquim, enquanto nas F12 e F13 não há rochas metamórficas da formação Frecheirinha.As quadras B1 e B2 apresentam duas unidades morfológicas (glint e superfície sertaneja) e possuem enquanto particularidade a presença de um fator estrutural caracterizado pela Falha Arapá. As quadras F12 e F13 abarcam as três unidades morfológicas do PNU. Por fim, é válido salientar a importância da quadra F13 que apresentou o maior valor individual, 19 pontos (as outras três quadras alcançaram 17 pontos), sendo a única do parque a apresentar registros fósseis e, dentre as quadras da classe muito alto, os três tipos de solos.

\section{CONSIDERAÇÕES FINAIS}

O índice de geodiversidade do Parque Nacional de Ubajara demonstrou que os maiores valores foram encontrados na porção central, área caracterizada pelo degrau geomorfológico entre o Glint da Ibiapaba e as Superfícies Sertaneja. Essa descontinuidade do relevo influencia ativamente na organização da rede de drenagem, na configuração dos solos e nas unidades morfológicas.

O presente estudo se apresenta como um esboço inicial para o entendimento da Geodiversidade do PNU. A base de dados primários com escalas pequenas, em especial os mapas de geologia e de solo, resulta em informações generalistas para a área. É necessário o mapeamento como melhor escala de detalhe 
das características abióticas do PNU. Somente com esse aprofundamento que a aplicação de um índice de Geodiversidade, como o proposto, poderá ser utilizado enquanto contributo efetivo ao Planejamento Ambiental.

Porém, mesmo com as limitações escalares apresentadas, o trabalho realizado pode ser utilizado pelo órgão gestor do Parque Nacional de Ubajara, enquanto uma ferramenta para indicar locais prioritários em pesquisas relacionadas à temática da geodiversidade. Ou seja, não como um fim, mas como um instrumento para auxiliar trabalhos futuros.

\section{REFERÊNCIAS}

ARRUDA, K. E. C.; BARRETO, A. M. F. Índice de geodiversidade do município de Araripina - PE, Brasil. Estudos geológicos, v. 25, n. 1, p. 103-117. Recife: 2015.

CAPUTO, M. V.; LIMA, E. C. Estratigrafia, idade e correlação do Grupo Serra Grande - Bacia do Parnaíba. In Anais do XXXIII Congresso Brasileiro de Geologia, Rio de Janeiro, p. 740-753, 1984.

CAVAlCANTE, J. C. Estratigrafia Precambriana do Estado do Ceará - Uma síntese. In Simpósio de Geologia do Nordeste. Natal, 1993. Atas... Natal, Boi. Núcleo Nordeste da SBG. v. 13. p. 313-316, 1993.

CHAMANI, M. A. C. Tectônica sinsedimentar no SiluroDevoniano da Bacia do Parnaíba, Brasil: O papel de grandes estruturas do embasamento na origem e evolução de bacias intracratônicas. Tese de doutorado apresentada ao Programa de Pós-Graduação em Geoquímica e Geotectônica, Universidade de São Paulo, 2015.

CENDRERO A. Propuesta sobre criterios para la clasificación y catalogación del patrimônio geológico. In El patrimonio geológico. Bases para su valoración, protección, conservación y utilización. Madrid: Centro de Publicaciones, Ministerio de Obras Publicas, Transportes y Medio Ambiente, p. 29-38, 1996.

CLAUDINO-SALES, V.; LIRA, M. V. Megageomorfologia do nordeste do estado do Ceará, Brasil. Caminhos de Geografia, v. 12, n. 38, p. 200-209. Uberlândia: 2011.

CPRM. Mapa de Geodiversidade Estadual do Ceará em escala de 1:1.000.000. Disponível em: www.cprm.gov.br/publique/GestaoTerritorial/Geodiversidade/Mapas-de-Geodiversi-dadeEstaduais-1339.html. Acesso em 19/04/2017.
EMBRAPA. Levantamento exploratório - Reconhecimento de Solos do Estado do Ceará em escala 1:600.000. Recife: Embrapa Solos, 1973.

MANOSSO, F. C. Potencialidades da paisagem na região da Serra do Cadeado-PR: Abordagem metodológica das relações entre a estrutura geoecológica, a Geodiversidade e o geoturismo. Tese de Doutorado apresentada ao Programa de Pós-Graduação em Geografia, Universidade Estadual de Maringá, Maringá, 2012.

MOURA-FÉ, M. M. Evolução geomorfológica da Ibiapaba Setentrional, Ceará: Gênese, modelagem e conservação. Tese de Doutorado apresentada ao Programa de PósGraduação em Geografia, Centro de Ciências, Universidade Federal do Ceará, 2015.

PEREIRA, D. I.; PEREIRA, P.; BRILHA, J.; SANTOS, L. Geodiversity assessment of Paraná State (Brazil): An innovative approach. Environmental Management, v. 53, n. 3, p. 542-552, 2013.

SANTOS, M. E. C. M.; CARVALHO, M. S. S. Paleontologia das bacias do Parnaíba, Grajaú e São Luís. Rio de Janeiro: CPRM Serviço Geológico do Brasil DGM/DIPALE - 2009. 215 p.

SERRANO, E.; RUIS-FLAÑO, P. Geodiversity. A theoretical and applied coneept. Geographica Helvetica, v. 62, p. 140147. Suiça: 2007.

SIQUEIRA, A. C. A. Geoquímica das lateritas do Domínio Médio Coreaú - Noroeste do estado do Ceará. Dissertação de Mestrado apresentada ao Programa de Pós-Graduação em Geologia da Universidade Federal do Ceará, , 2011.

VAZ, P. T.; REZENDE, N. G. A. M.; WANDERLEY FILHO, J. R.; TRAVASSOS, W. A. S. Bacia do Parnaíba. Boletim de Geociências da Petrobrás, v. 15, n. 2, p.253-263. Rio de Janeiro: 2007.

\section{AGRADECIMENTOS}

O presente trabalho foi realizado com apoio da Coordenação de Aperfeiçoamento de Pessoal de Nível Superior - Brasil (CAPES) por meio de bolsas de Doutorado-PROEX (Código de financiamento: 88882.180701/2018-01) e de Doutorado Sanduíche no Exterior (Código de financiamento: $88887.364301 / 2019-00$ ) concedidas ao primeiro autor.

Recebido em: 23/04/2020

Aceito para publicação em: 14/05/2021 